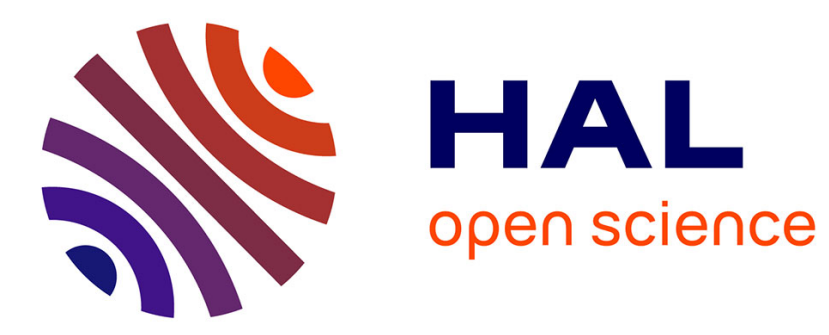

\title{
TRAFFIC ACCIDENTS, DEATHS AND ALCOHOL CONSUMPTION
}

\author{
Jose Maria Arranz, Ana Isabel Gil
}

\section{To cite this version:}

Jose Maria Arranz, Ana Isabel Gil. TRAFFIC ACCIDENTS, DEATHS AND ALCOHOL CONSUMPTION. Applied Economics, 2009, 41 (20), pp.2583-2595. 10.1080/00036840701222652 . hal00582153

\section{HAL Id: hal-00582153 \\ https://hal.science/hal-00582153}

Submitted on 1 Apr 2011

HAL is a multi-disciplinary open access archive for the deposit and dissemination of scientific research documents, whether they are published or not. The documents may come from teaching and research institutions in France or abroad, or from public or private research centers.
L'archive ouverte pluridisciplinaire HAL, est destinée au dépôt et à la diffusion de documents scientifiques de niveau recherche, publiés ou non, émanant des établissements d'enseignement et de recherche français ou étrangers, des laboratoires publics ou privés. 


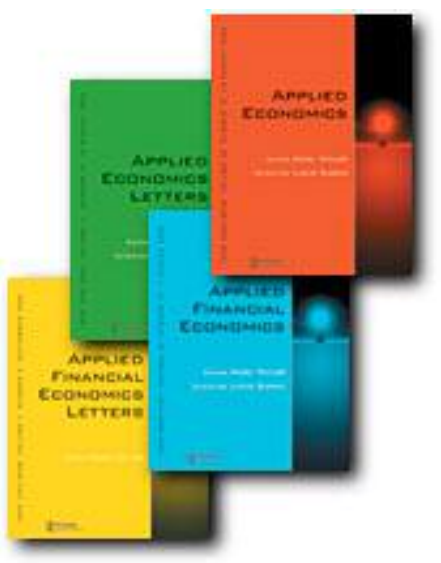

TRAFFIC ACCIDENTS, DEATHS AND ALCOHOL CONSUMPTION

\begin{tabular}{|r|l|}
\hline Journal: & Applied Economics \\
\hline Manuscript ID: & APE-06-0409.R1 \\
\hline Journal Selection: & Applied Economics \\
\hline JEL Code: & $\begin{array}{l}\text { C10 - General < C1 - Econometric and Statistical Methods: General } \\
\text { <C - Mathematical and Quantitative Methods, R41 - } \\
\text { Transportation: Demand|Supply|Congestion |Safety and Accidents < } \\
\text { R4 - Transportation Systems < R - Urban, Rural, and Regional } \\
\text { Economics, I10 - General < I1 - Health < I - Health, Education, and } \\
\text { Welfare, H00 - General < H0 - General < H - Public Economics, C50 } \\
\text { - General < C5 - Econometric Modeling < C - Mathematical and } \\
\text { Quantitative Methods }\end{array}$ \\
\hline Keywords: & $\begin{array}{l}\text { Alcohol Consumption, Traffic Accidents, Fatalities, Traffic Measures, } \\
\text { Alcohol Taxes }\end{array}$ \\
\hline
\end{tabular}

\section{s) ScholarONE" \\ Manuscript Central}




\title{
TRAFFIC ACCIDENTS, DEATHS AND ALCOHOL CONSUMPTION
}

\author{
Arranz*, J.M. and Gil ${ }^{\star}$, Ana I.
}

\section{October 2006}

\begin{abstract}
The main goal of this paper is to analyze the relationship existing among prices of alcoholic beverages, alcohol consumption and traffic fatalities for the Spanish Autonomous Communities during the time interval 1998-2002. Among the main results, we highlight a positive correlation between alcohol consumption and traffic mortality rate. Basically, governments implement two kinds of policies to reduce the traffic mortality rate. One is oriented to control the supply of alcohol by increasing alcohol taxes. The other is oriented to preserve traffic security, increasing the number of sanctions for traffic rule infraction. We find evidence that both policies exert a positive influence in the reduction of traffic fatalities. There is no empirical evidence to indicate that being a novice driver increases the tendency to be involved in a mortal traffic accident.
\end{abstract}

Keywords: Alcohol Consumption, Traffic Accidents, Fatalities, Traffic Measures, Alcohol Taxes.

JEL Classification: C3, H2, I1, R4.

\footnotetext{
- University of Alcalá, Departamento de Estadística, Estructura Económica y OEI. Plaza de la Victoria 3, Alcala de Henares, Madrid, 28803, Spain.E-mail: josem.arranz@uah.es

- Cornell University. Department of Policy Analysis and Management. Martha Van Rensselaer Hall. Ithaca 14850 (NY) USA.E-mail: aig24@cornell.edu
} 


\section{INTRODUCTION}

Traffic accidents have become one of the most serious health problems of modern societies due to the number of deaths and handicaps that this kind of accident generates. Road fatalities are influenced by the quality and kind of vehicle used for transportation, so for instance, the repercussions of a traffic accident in which motorcycles are involved are usually more dangerous for the individual than those traffic accidents in which cars are implicated (Scuffham, 2003; Smith, 1999). The quality and coverage of the vehicle helps undoubtedly to reduce the impact of the accidents, however in traffic accidents in which excess speed and/or alcohol abuse are present, the security systems of the vehicles serve for little. In fact, these are the two most frequent reasons for traffic accidents (Spanish General Directorate of Traffic, 2004).

The Spanish General Directorate of Traffic (2005) estimates that in Spain there are around 3,000 mortal traffic accidents per year which cause the death of 5,000 people. With data provided from the Spanish General Directorate of Traffic, a Spanish newspaper highlights that: "more than $30 \%$ of traffic accidents during 2004 involved drivers who presented a Blood Alcohol Content (BAC) over the legal level" (see Spanish newspaper El Pais, December 07, 2005). The magnitude of this problem is so severe that for example drunk drivers are directly responsible for one in four deaths among young males aged from 15 to 29 (Spanish National Anti-Drug Campaign, 2001) ${ }^{1}$.

One of the main contributions accomplished by the economic analysis perspective in the research of alcohol consumption lies in the fact that if we only consider present monetary

\footnotetext{
${ }^{1}$ In all these statistical numbers a distinction could not be made between traffic fatalities caused by the driver's own fault (e.g. death of drunk driver) or those caused by someone else's fault (e.g. drunk drivers kills other person). From the report of the Spanish General Directorate of Traffic (2005), we conclude that to analyse drunk driving, it is important to know the number of drivers who drove under the influence of alcohol, and the number of people who died as a consequence of having been involved in a traffic accident independently whether the person who died caused the traffic accident or not. So unless the contrary is said, the number of victims refers to
} 
prices of alcoholic beverages, we are undervaluing the real cost of alcohol consumption. Next to the monetary dimension, problems derived from alcohol abuse should be valued (accidents, health problems or social conflicts, among others). The costs that alcohol drinkers impose on themselves and the people who surround them are the foremost reason why alcoholic beverages, except wine $^{2}$, are burdened with special indirect taxes. Indirect taxes are transferred integrally to the final price of the product, so only consumers pay the tax. One of the governmental justifications of a price increase is to make consumers aware of the real costs related to alcohol consumption. This argument is particularly relevant to drinking where there are serious short and long term dangers. Not everybody values these potential costs in the same way; in fact, young people tend to give them less importance because they have less money than adults (Grossman et al., 1993). This differential sensibility means that if the final price of alcoholic beverages increases, their consequences will be higher for youth. Thus abusive alcohol consumption is promoted by the fact that the prices that consumers pay are lower than marginal social costs of alcohol consumption; it is necessary to increase the taxes on alcoholic beverages until the consumer realizes about the real cost of drinking alcohol (Phelps, 1988). Cook (1988) supports this argument, if and only if abusive alcohol consumption and its corresponding costs were sensitive to the price of alcoholic beverages.

Therefore, it is relevant to analyze the relationship between alcohol consumption and its negative consequences, so policy makers can foresee how an increase in the taxation of alcoholic beverages reduces alcohol consumption. In fact the scientific literature about the effectiveness of alcohol taxation for the reduction of traffic fatalities has been increasing in the last years (Cook and Tauchen, 1984; Dee, 1999; Dee et al., 2005; Grossman et al., 1993; Mast et al., 1999; Ruhm, 1995 and 1996; Saffer and Grossman, 1987; Young and Bielinska-

the total number of people who died as a consequence of having been involved in a traffic accident in which the driver presented a BAC higher than that permitted. 
Kwapisz, 2006; Young and Likens, 2000). Nevertheless we fail to notice empirical evidence under a European context, so our main contribution lies in providing the first empirical estimations for Spain.

As a starting point we study some basic statistics that provide us with a preliminary glimpse of the problem. In Table 1, we show the numbers and percentage of traffic fatalities (and deaths) with respect to population for Spanish Autonomous Communities for the time period 1996-2002. From Table 1, we appreciate that there are around 5,000 traffic fatalities per year. In relative terms, we appreciate that between one and two deaths in 100 are derived from traffic accidents and one person from 10,000 citizens dies because of traffic accidents. The communities with a higher percentage of traffic fatalities with respect to population and total number of deaths are Aragon, Castilla-León, Galicia, Murcia, Rioja and Navarra. In contrast, Cantabria and Madrid are the regions with the lowest percentages. With regard to the temporal evolution, we observe that the number of traffic fatalities with respect to the total number of deaths increases in all Autonomous Communities during the time interval considered, being specially high up to the year 2000. This increase of traffic fatalities is a problem that worries the Spanish Society and Public Institutions.

\section{(Insert Table 1)}

The main goal of this paper is to analyze the relationship existing among alcohol consumption, prices of alcoholic beverages and traffic accidents in Spain. In particular, we focus on investigating the effectiveness of diverse economic policies (alcohol taxes) and traffic policies (sanctions) that are applied with the purpose of reducing the number of traffic fatalities. The most important contribution of this paper lies in its being the first economical analysis that goes deeply into the relationship between drinking and driving for the Spanish

\footnotetext{
${ }^{2}$ Wine products have been exempt from special indirect taxes to protect the competitiveness of European wine
} 
case. Economic theory states that alcohol consumption is negatively correlated with the price of alcoholic beverages, so an increase in these prices, ceteris paribus, reduces alcohol consumption, and consequently, the number of traffic fatalities. Therefore, the hypothesis we want to verify is:

Alcohol Prices $\rightarrow$ Alcohol Consumption $\rightarrow$ Traffic Fatalities.

To that end, we define a theoretical model that combines theories of addiction and crime. For the empirical analysis, we have drawn data from Consumption Household Survey (Spanish Ministry of Food, Agriculture and Fishing); Survey of Deaths by Cause and Harmonized Consumption Index (Spanish National Institute of Statistics); Statistic Yearbook about Labor Issues (Spanish Labor Ministry) and Statistic Yearbook (General Directorate of Traffic).

The rest of the paper is structured as follows. In Section 2 we present the previous theoretical and empirical researches. Section 3 is devoted to the theoretical model. In Section 4 we detail the empirical framework and database. In Section 5 we explain the results of the estimations. Finally, in Section 6, we summarize the main conclusions and we suggest corresponding policy implications.

\section{THEORETICAL AND EMPIRICAL LITERATURE REVIEW}

In previous papers, authors analyze the determinants of traffic accidents, paying special attention to the effects of traffic sanctions, alcohol consumption and alcohol taxes. The main argumentation line establishes that offences committed by individuals are negatively correlated with their costs. So offences can be defined as a function of the probability of being arrested and punished, as well as the severity of the punishment. Several empirical studies 
have demonstrated that harder traffic sanctions contribute to increasing the cost of the offence of driving under the influence of alcohol, so this kind of traffic offence will experience a reduction, and therefore, traffic fatalities will be reduced too (Young and Likens, 2000). Other empirical studies question the effectiveness of harder sanctions because of two main reasons: an incorrect transmission of new penalties so that a population group remains unaware of the latest sanctions, and the laxness of present penalties. For that reason, it is necessary to increase the penalties until they reach their real social costs (Kenkel, 1993a; Kenkel and Koch, 2001). Next to penalization, the probability of being arrested plays an outstanding role in the reduction of drinking and driving (Benson et al., 1999).

Although drunk driving may seem irrational, it is not wrong to model the co-joint decision of drinking and then driving under the structure of rational theories. The models in which individuals maximize their utilities are applicable to criminal behaviour, which includes driving under the influence of alcoholic beverages (Becker, 1968). In fact, there is strong empirical evidence about the positive link between alcohol consumption and the number of traffic accidents. Among priority measures that should be implemented, we underline the reduction of alcohol abuse. In fact, most governments frequently recur to increasing alcohol taxes which raises the final price of alcoholic beverages, and consequently, reduces alcohol demand as the acquisition capacity is restrained (Young and BielinskaKwapisz, 2006). Nevertheless, the effectiveness of policies centred on tax increases is under debate. Whereas it is an efficient policy for some authors (Benson et al.,2000; Ruhm, 1995 and 1996; Young and Bielinska-Kwapisz, 2002), for others, tax effects are limited due to the existence of fixed spatial effects ${ }^{3}$ (Dee, 1999; Mast et al., 1999) or due to the occurrence of measurement errors at the time of calculating alcohol prices (Young and Bielinska-Kwapisz,

\footnotetext{
${ }^{3}$ These papers have analyzed the traffic accidents in USA where the fixed spatial effects are related to the different States.
} 
2003), or even due to the presence of alcohol consumption in early stages of life (Sloan et al., 1994).

With the goal of postponing the age at which young people start their experience with alcoholic beverages, the minimum legal age for buying alcoholic beverages has been frequently raised. Making access to alcoholic beverages more difficult for youth will reduce the tendency of drunk driving for at least this population group (Cook and Tauchen, 1984). However, this idea is questioned by Asch and Levy (1987), who concede greater importance to the experiences of driving and drinking than to the minimum legal age for buying alcoholic beverages.

Lastly, there are authors who, although they recognize the impact of alcoholic consumption over the number of traffic accidents, also suggest improving vehicle security to reduce traffic mortality rates, such as for example, controlling the use of seat belts or helmets (Sen, 2001).

\section{THEORETICAL MODEL}

To define the theoretical model we take as a starting point the article of Mast et al. (1999), in which the number of deaths by traffic accidents ${ }^{4}(R)$ depends on drunk driving offences $(D)$ and a vector that includes measures of traffic such as new expedited driving licenses, that is, the number of people with newly acquired driving licenses $(T)$ :

$$
R_{t}=R\left(D_{t}, T_{t}\right)
$$

The main problem with equation (1) is that $D$ is not observable, so there is no data available for drunk driving. To solve the maximization problem, we focus on the pattern that

\footnotetext{
${ }^{4}$ The number of deaths by traffic accidents reflects the total number of people who died as a consequence of having been involved in a traffic accident independent of whether they provoked it or not.
} 
defines drunk driving. The function that explains driving under the influence of alcohol (D) includes alcohol consumption $(C)$, and expected punishment for drunk driving. The punishment is determined by the probabilities of being arrested and fined $(F)$, and by the punishment severity $(S)$ :

$D_{t}=D\left(C_{t}, F_{t}, S_{t}\right)$

We just substitute the $D$ expression in (1)

$R_{t}=R\left(C_{t}, F_{t}, S_{t}, T_{t}\right)$

where $C$ is determined by a Marshallian demand function which takes into account the additive characteristics of tolerance and reinforcement (Becker and Murphy 1988) ${ }^{5}$ :

$C_{t}=C\left(P_{t-1}, P_{t}, P_{t+1}, I\right)$

$I$ represents initial wealth and total life incomes valued at the initial moment and $P_{t}$ is the price of alcoholic beverages for the moment of time $t$. If alcohol consumption depends on the present, past and future prices of alcoholic beverages, then the individual takes decisions rationally because at the moment of deciding how much to drink, past alcohol consumption determines present demand and present consumption affects future demand. If alcohol consumption depends exclusively on the present and past prices of alcoholic beverages, then the individual takes decisions myopically, because current consumption is independent of

\footnotetext{
${ }^{5}$ The modelling of traffic accidents as a function of alcohol consumption, equation (3), is not exempt of weaknesses. For instance, whether alcohol consumption increases the probability of a traffic accident depends on: when the alcohol is consumed (just before driving); where the alcohol is consumed (e.g. at home or away from home, with dinner); and how much alcohol is consumed in a short period of time. So two people, or two regions or two countries, can have the same amount of alcohol consumption, but very different levels of traffic risk. Regularly drinking a glass of wine with dinner may not be a problem; drinking 7 glasses of beer on a Friday night could cause a drunk driving accident.
} 
future consumption and/or future events. The main difference between rational and myopic points of view is that the latter is entirely backward-looking (Becker et al., 1994).

Models of drunk driving characterized by an economic perspective tend to emphasize the impact of alcohol taxes on the crime prevalence versus police efforts to combat drunk driving. Benson et al. (2000) show that police can indeed deter drunk-driving by using aggregated data that includes variables such as drug arrests, property arrest and violent arrest. To measure the probability of being arrested, we will introduce the annual number of traffic sanctions registered by the policy.

For the North-American society, there are more complex models that consider the influence of other variables, for instance legislative, in the process of utility maximization. This complexity is derived from the fact that the diverse States are self-ruling to implement health and traffic public policies (Benson et al., 2000; Dee et al., 2005; Kenkel et al., 2001; Morrisey and Grabowski, 2005; Pacula 1998). Kenkel and Koch (2001) highlight that new state laws will be effective in the deterrence of drunk driving, only if people know about them. In fact, although new state laws have been implemented and their efficiency is under question, there is evidence of rational behaviour given the lack of knowledge of these laws among citizens.

For the empirical application of the Spanish case (1998-2002), there have not been substantial legislative changes. Concerning alcohol issues, the minimum legal age for buying alcoholic beverages has been increased from 16 to 18 years in most of the Autonomous Communities. The Spanish Autonomous Communities are self-governing to determine the minimum legal age for the purchase of alcoholic beverages, so the rise of this legal age has taken place in different communities at different times. For example, Catalonia and Navarre were the first communities to adopt this policy in 1991, whereas Aragon and Rioja were some 
of the last ones to adopt the policy in 2001. Nevertheless, we do not introduce this policy measure in our model, because it is necessary to be at least 18 years old to have access to a driver's license. Concerning traffic measures in Spain, one of the main legal changes has been to reduce the allowed BAC from 0.8 grams per litre in 1992 (Royal Decree 13/1.992, of January 17) to 0.5 grams per litre in 2003 (Royal Decree 1428/2003, of November 21). So only when we have available data of traffic accidents for the year 2003 and after, will it be possible to analyze the effectiveness of this policy. Concerning traffic sanctions, there are four legislative documents (Legislative Royal Decree 339/1.990, of March 2; Law 5/1997, of March 24; Law 19/2001, of December 19; Law 17/2005, of July 19) in which the character of driving is established with higher levels of the legal BAC (serious infraction and very serious infraction since 2001) and the monetary and non monetary penalties (maximum 600 Euros). We observe that the infraction of drunk driving is redefined from serious to very serious, but the monetary penalty is scarcely raised by 2 Euros from the Legislative Royal Decree of 1990 and the Law of 2001, thus we consider that the offender faces the same sanction along the studied period of time. According to this argumentation line the variable $S$ keeps constant along the period 1998-2002, so we will introduce it under the constant term to avoid problems of multicollineality. Once we have obtained the optimal consumption of alcoholic beverages, we will translate the result into the following function to obtain the rate of traffic fatalities:

$$
R_{t}=R\left(C_{t}, P_{t}, T_{t}\right)
$$

from which we will analyze the impact of alcohol consumption, traffic sanctions and the rest of traffic measures in the formation of the rate related to traffic fatalities. The empirical results will confirm if a lower demand of alcoholic beverages reduces the mortality rate by traffic accidents. 


\section{EMPIRICAL MODEL AND VARIABLES}

Regarding to the empirical model, we will structure the estimations in two stages. In the first stage, we will think about the determinants of alcohol consumption per capita. Among these determinants we draw attention to the price of alcoholic beverages for the present, past and future time periods, individual incomes and dummy variables that summarize fixed temporal and spatial effects. In a second stage, we will define the rate of traffic fatalities as a function of alcohol consumption, the number of traffic sanctions (proxy variable of sanctions and traffic measures) and the attainment of a new driving license. In addition, we introduce dummy variables to introduce fixed effects related to the different Autonomous Communities and time periods ${ }^{6}$ in both stages. So equations (4) and (5) will adopt the following formulations:

$C_{i t}=Z_{i t} \phi+w_{i t} \quad \mathrm{i}=1,2, \ldots 18 ; \mathrm{t}=1998, \ldots 2002$.

$R_{i t}=C_{i t} \alpha+X_{i t} \beta+v_{i t} \quad \mathrm{i}=1,2, \ldots 18 ; \mathrm{t}=1998, \ldots 2002$

where $\mathrm{C}_{\mathrm{it}}$ represents the consumption of alcohol per capita for the Autonomous Community $i$ for the year $t$; $\mathrm{R}_{i t}$ is the rate of traffic fatalities; $\mathrm{X}_{\mathrm{it}}$ and $\mathrm{Z}_{\mathrm{it}}$ are matrices of explicative variables; $\beta, \alpha$ and $\phi$ are vectors of parameters; $\mathrm{w}_{\mathrm{it}}$, and $\mathrm{v}_{\mathrm{it}}$ are residuals which summarize the unobserved aspects that influence both alcohol consumption and traffic fatalities. For instance, the residual of the equation of traffic fatalities will include human failure or weather conditions, among others.

\footnotetext{
${ }^{6}$ The mortality rate of traffic fatalities is the best empirical approximation to analyze the relationship between alcohol consumption and traffic fatalities (Young and Likens, 2000; Young and Bielinska-Kwapisz ,2006).Although all traffic accidents are not the result of drunk driving, there is a strong correlation between both variables.
} 
The most common specification ${ }^{7}$ of the dependent variable $\mathrm{R}_{i t}$ in the equation of the mortality rate (7) consists in a logistic transformation of this variable. That is, if $r_{i t}$ is obtained for the Autonomous Community $i$ as the number of deaths in traffic accidents divided by the Community population for each year $t$, then the dependent variable in the regression is $R_{i t}=\left(r_{i t} /\left(1-r_{i t}\right)\right)$. One advantage of this transformation lies in that it restrains the foresee values of the mortality rate to 0 and 1 .

We also assume that unobservable components that influence traffic fatalities may be unique for each Autonomous Community and constant over time. Additionally, there may also be specific unobservable aspects for each year ${ }^{8}$. Thus the residual in equation (7) should be transcribed as $v_{i t}=\varphi_{i}+\lambda_{t}+\varepsilon_{i t}$; where $\varphi_{i}$ represents the unobservable fixed effects for each Autonomous Community, $\lambda_{\mathrm{t}}$ the fixed effect for each year and $\varepsilon_{\mathrm{it}}$ the error term whose variance is constant and uncorrelated with observable and unobservable characteristics for the Autonomous Communities through time. The same argumentation line may be translated to the unobservable aspects that influence the alcohol consumption, so the residual in equation (6) should be transcribed as $\mathrm{w}_{\mathrm{it}}=\pi_{\mathrm{i}}+\theta_{\mathrm{t}}+\rho_{\mathrm{it}}$, where $\pi_{\mathrm{i}}$ is the specific unobservable component for each Autonomous Community, $\theta_{\mathrm{t}}$ the fixed effect for each year and $\rho_{\text {it }}$ the error term whose variance is constant and uncorrelated with observable and unobservable characteristics through time. The specific unobservable fixed effects for each Community and year are summarized under dummy variables for each Community and year.

Concerning the estimation method, we will take into account the following distinctions. We estimate equation (6) applying OLS, thus the right hand of the equation only contains exogenous variables $(Z)$ and additionally these variables are not correlated with the

\footnotetext{
${ }^{7}$ Other useful specification lies in the Linear Regression Models. Young and Likens (2000) compare the results of both specifications (linear and logistic) finding just small differences. We have also carried out estimations from both specifications concluding that the results are very similar. Results are available on request.
} 
residual $\mathrm{w}_{\mathrm{it}}$, so all assumptions of the classic OLS are satisfied. Regarding equation (7), we highlight that the endogenous variable $\mathrm{C}$ is introduced as an explicative variable next to the rest of the independent variables that configure $\mathrm{X}$. Under these circumstances, OLS can also be implemented, only if, $\mathrm{C}$ were not correlated with the residual $\mathrm{v}_{\mathrm{it}}$. To find out whether there is correlation or not, we carry out two tests: the endogeneity, or simultaneity, test of Hausman (1978) and the Augmented Test Regression, also known as Durbin-Wu-Hausman (DWH) of Davidson and Mackinnon (1993) also based on the asymptotic requirement of the Hausman test ${ }^{9}$. The results of both tests are presented in Table 2, in which the first column is devoted to the Hausman test and the second, to the DWH test. Both tests fail to reject the null hypothesis of exogeneity, thus alcohol consumption is an exogenous variable in equation (7). In the way that the alcohol consumption variable is not correlated with the residual, the OLS estimators are consistent and asymptotically efficient. In summary, the two-equation-system is recursive, so we will estimate two independent equations by OLS because it is not necessary to apply the methodology of simultaneous equations (Greene, 2003, section 15.5.1).

\section{(Insert Table 2)}

Lastly, due to the small number of observations (90 observations corresponding to 18 Autonomous Communities for the time interval 1998-2002) we also test if the estimated parameters might be biased by a problem of heteroskedasticity. Once we checked and rejected the possibility of heteroskedasticity ${ }^{10}$, we continued with the presentation of the results by using OLS.

The database has been self-elaborated by using information drawn from the Consumption Household Survey (Spanish Ministry of Food, Agriculture and Fishing); Survey

\footnotetext{
${ }^{8}$ Both assumptions are recurrent in the literature; see for example the articles of Mast et. al (1999), Young and Likens (2000) and Young and Bielinska-Kwapisz (2006).

${ }^{9}$ The Augmented Test Regression and Hausman Test are included in the software package Stata 9.0. More information about these tests is available in: http://www.stata.com/support/faqs/stat/endogeneity.html.
} 
of Deaths by Cause and Harmonized Consumption Indexes (Spanish National Institute of Statistics); Statistic Yearbook about Labor Issues (Spanish Labor Ministry) and the Statistic Yearbook (General Directorate of Traffic).

\section{(Insert Table 3)}

Table 3, contains the mean and standard deviation of each variable, which have been classified by sources. The period of time considered is from 1998 to 2002. Regarding the variables related to consumption and acquisition capacity, we observe that on average an individual demands $53.56 \mathrm{Kg}$. of alcoholic beverages per year, and the labour cost per capita is 1,313.932 Euros per month. The Price Index of Consumption (CPI) is, with an index of 108.580, superior to the corresponding past CPI (105.205) and lower than the corresponding future CPI (109.001). Concerning traffic conditions, there were 133 traffic sanctions for every 1000 citizens, and on the other hand, a new driving license A or A1 was expedited for every 1000 citizens. Regarding geographical distribution, $27.8 \%$ of the observations are for Autonomous Communities that reside in the North, $22.2 \%$ for Communities allocated in the Center, $16.7 \%$ for Communities placed in the South and East, $11.1 \%$ for the Islands and the remaining 5.6\% for Madrid.

One of the peculiarities of the model is that we focus on the previous number of sanctions instead of the present number of traffic sanctions, so the variable is retarded one $\operatorname{period}^{11}$.

\footnotetext{
${ }^{10}$ To check the presence of heteroskedasticity we carry out the test of White and the test of Breuch-Pagan/CookWeisburg which are also available in the software package Stata 9.0. Both test results are algebraically identical and are available from the authors upon request.

${ }^{11}$ The temporal interdependency of alcohol consumption derived from the Addiction Theory (Becker and Murphy, 1988) postpones the effect of public policies, thus the individual requires a period of time to adjust to the new changes in the parameters that define alcohol consumption (McKenzie, 1991).
} 


\section{RESULTS.}

We will keep the sequence defined in the theoretical framework for the presentation of the results. Thus, we start with the estimation of alcohol consumption under rational and myopic addition. Both equations differ from each other only in the introduction of the future price of alcoholic beverages .To that end, we have repeated the estimations by OLS twice, in order to know if the pattern of alcohol consumption is defined as rational or myopic. Then we will continue with the estimation of traffic mortality rate.

Table 4, contains estimation results for alcohol consumption according to the theories of rational addiction and myopic addiction. In this table, we observe that the lagged price of alcoholic beverages is negatively correlated to the present alcohol consumptions. Thus, an increase of $1 \%$ in the lagged price of alcohol reduces alcohol consumption by $0.61 \%$. This value is within the range of price elasticities for aggregate alcohol consumption estimated in previous work (Young and Bielinska-Kwapisz, 2003, 2006). Furthermore, if for instance the individual foresees a $1 \%$ increase in the future price of alcoholic beverages, he/she will tend to increase his/her present alcohol consumption in a $0.17 \%$, but we have to be cautious with this affirmation because the estimated parameter is not statistically significant. In addition to the lack of significance of future alcohol price, we observe that although the adjusted coefficient of determination is slightly higher for the myopic model (and the Akaike info criterion slightly lower), we can not strongly affirm that the pattern of alcohol consumption for the Spanish society behaves myopically rather than rationally.

\section{(Insert Table 4)}


Concerning other monetary variables, we observe that higher available budgets promote higher demand for alcoholic beverages. So, for instance, an increase of a $1 \%$ increase in the monthly income ${ }^{12}$ raises the demand for alcohol by $0.53 \%$. per year.

In relation to spatial and temporal effects, we observe that alcohol consumption per capita is higher in all areas in relation to Madrid, with the higher marginal effect for those regions allocated in the South followed by the North and East. On the other hand, alcohol consumption experienced the highest marginal effect increase in 1999 in relation to 2001, while during 2000 and 2002, alcohol consumption experienced a reduction. Nevertheless, the effects of these last two dummy variables are not statistically significant.

Once having analyzed the demand of alcoholic beverages, we proceed with the presentation of the results related to traffic fatalities in Table 5 using two different specifications for equation (7). Model 1, includes alcohol consumption as regressor and Model 2 repeats again the estimation of traffic mortality rate but this time, including as a regressor, the price of beer. In Model 1 we appreciate that higher traffic control, measured by the lagged number of traffic sanctions registered by police, is negatively correlated with the rate of traffic fatalities, so for example an increase in traffic sanctions ${ }^{13}$ by $10 \%$ reduces the rate of traffic fatalities by $0.34 \%$. So, a higher public expenditure allocated in stronger traffic control will have a positive effect in the reduction of traffic fatalities.

\section{(Insert Table 5)}

Another determinant, cited recurrently as a source of traffic accidents, is the lack of driving experience; therefore we introduce a variable that informs us about the number of new drivers in each Autonomous Community. Contrary to what we would have expected, this

\footnotetext{
${ }^{12}$ We have recurred also to the Gross National Product (GNP) with which we have obtained similar estimations to that described in the present paper.

${ }^{13}$ The variable related to traffic sanctions informs us of the number of sanctions expedited by the Policy as a consequence of traffic controls.
} 
population group does not increase the tendency to suffer a traffic accident, which we analyze as deriving from two facts. Novice drivers have lower speed limits during the first year, and lower legal BAC for the first two years ${ }^{14}$. In fact, an increase of $10 \%$ new drivers reduces the rate of traffic fatalities by $0.23 \%$.

By region, we observe that coherent with the alcohol consumption levels, the rate of traffic fatalities is higher for all areas with respect to Madrid. Nevertheless, the Communities allocated in the South and the Islands have the highest mortality rate.

But undoubtedly, the most interesting result is the one that confirms that higher alcohol consumption per capita increases the rate of traffic fatalities. So an increase of alcohol demand by $1 \%$ provokes an increase of $0.305 \%$ in the number of traffic fatalities. This result, next to the fact that an increase in the lagged price of alcoholic beverages reduces the present demand of alcohol, allows us to affirm that an increase in the price of alcoholic beverages reduces the rate of traffic fatalities. By definition, the elasticity fatalities with respect to the price of alcohol, $\mathrm{E}_{\mathrm{fp}}$, is equal to the product of the price-consumption elasticity, $\mathrm{E}_{\mathrm{cp}}$, and the consumption-fatality elasticity, $\mathrm{E}_{\mathrm{fc}}$. This implies that the price-fatality elasticity is $\mathrm{E}_{\mathrm{fp}}=0.615 * 0.305=0.187 \cong 0.19$. So an increase of the lagged alcohol price in $1 \%$ reduces the number of traffic fatalities by $0.19 \%$. This is the first paper that calculates the price-fatality elasticity for the particular case of a European country; however this magnitude has already been obtained for the North-American society. Thus, the relationship between alcohol price and number of traffic fatalities is also negative and the absolute value of the price-fatality elasticity falls in a range of 0.5 to 1.0 in USA (Kenkel, 1993; Young and Bielinska-Kwapisz 2006).

\footnotetext{
${ }^{14}$ Novice drivers are not allowed to drive with BAC higher than 0.3 for the first two years (Royal Decree 1428/2003, of November 21).
} 
Lastly, we repeat again the estimation of traffic mortality rate but this time including as a regressor the price of beer (Model 2). The reason why we introduce the beer price is to observe the influence of an increase in the price of a particular alcoholic beverage on the number of traffic fatalities (Young and Likens, 2000; Young and Bielinska-Kwapisz, 2006). At the same time, as we failed to reject the null hypothesis of exogeneity of alcohol consumption (previously mentioned in page 13), so to confirm this hypothesis is important to consider the statistical power of the test. If the instrumental variables are not very strong, the Hausman test is weak and will fail to reject exogeneity. In order to carry out a robustness test, we estimate the reduced form, Model 2, where consequently the potentially endogenous variable (alcohol consumption) has been replaced with an exogenous determinant of alcohol consumption, that is, the price of beer. According to the price-fatality elasticity, we conclude that if the tax applied to beer increases in $10 \%$, the rate of traffic fatalities will drop by $6.9 \%$, which is the result of multiplying the increase in the price of the beer as a consequence of the tax increase ${ }^{15}$ by the price elasticity of Model 2 in Table 5 . Furthermore, we observe that the parameter of the beer price is strongly accepted under a significance level of 5\%, so we do not have any signal that the Hausman test is weak.

Once our theoretical model has been validated for both general price of alcoholic beverages and the price of a particular alcoholic beverage, it is reasonable to support the strategy of incrementing alcohol taxes in order to reduce their negative externalities.

\section{CONCLUSIONS AND POLICY IMPLICATIONS}

Although the consumption of legal drugs, such as alcoholic beverages, is not considered as pernicious as the consumption of illegal ones, the real situation is that alcohol

\footnotetext{
${ }^{15}$ Alcohol taxes are fully passed through to final prices (Kenkel, 2005). Taking into account that the Spanish tax rate applied to beer is around $16.75 \%$ of the final price (including all indirect taxes, that is VAT and special tax),
} 
consumption promotes serious health problems. One of the main contributions of this paper lies in being the first economic analysis that demonstrates the positive relationship between alcohol consumption and the number of traffic fatalities for the Spanish case. Drug control and prevention has become mainly a responsibility of governments which usually restrain their policies to market regularization (Reuter, 1988). Due to the fact that taxes are the most applied public policy instrument for reducing alcohol abuse, we have analyzed the effectiveness of a price increase. Next to economic policies, we have also introduced traffic measures such as a higher traffic control through an increase in the number of traffic sanctions. The empirical evidence validates our main hypotheses: an increase in alcohol prices reduces alcohol consumption, and consequently, the number of traffic fatalities. On the other hand, a higher number of traffic sanctions reduces the rate of deaths by traffic accidents. In the way that a higher number of traffic sanctions has a positive influence, it is surprising that economical sanctions have been kept constant since their introduction (max. 600 Euros), and considering the serious magnitude of the negative externalities of drunk driving, this monetary penalty can even be considered quite indulgent.

Although governments can rarely hope to reduce risks to zero, they can aim to lower them to a more acceptable level, and to explain, through open communication with the public, why and how they are doing so. On the one hand, there is a global tendency towards increasing taxes in order to limit alcohol consumption, while on the other hand some domestic production is being protected. For example, the tax harmonization process of the European Union reveals that Mediterranean countries tend to apply lower tax rates to wine as opposed to alcoholic beverages, and furthermore, wine producers receive subsidies from the European Commission to help them compete with countries outside the European Union. There is a debate about the justification for these policies. In particular, Eastern-European countries,

an increase by $10 \%$ of the beer taxes will increase the final price of the beer by more or less $9.4 \%$ (Law $37 / 1992$ 
which have recently joined the European Union, are requesting the same privileges for their beer industry that is currently granted to the wine sector. In order to avoid domestic subsidies, an alternative approach is to impose import taxes. For example, this is the way the USA has protected their local wine industry.

On the other hand, one of the main sources of public income is tax collection. Because the demand for alcoholic beverages tends to behave as inelastic, an increase in the corresponding taxes might be more beneficial in terms of increasing public revenue than in terms of reducing alcohol abuse.

In addition, these economic and traffic measures are not the only ones that promote welfare, the policy makers have a wide range of possibilities, such as promoting healthy leisure activities as an alternative to alcohol consumption. So although decisive steps have been implemented in the fight against alcohol abuse and drunk driving, the magnitude of these policies is still uncertain, such as for example a decrease in the BAC. It is also worthy to draw attention to alternative actions such as the removal of driving licenses in the case of risky driving.

\section{ACKNOWLEDGEMENTS.}

The authors are indebted to the anonymous referee and Donald S. Kenkel for their valuable comments in previous versions of this paper. An earlier draft has been published as a working paper by FUNCAS, so the authors appreciate the recommendations received by this institution. Finally, the authors would like to express their thanks for the financial support provided by the Spanish Ministry of Education. The usual disclaimer applies.

of December 29 and Law 38/1992 of December 28). (See Table 6)

Editorial Office, Dept of Economics, Warrwick University, Coventry CV4 7AL, UK 


\section{References:}

Asch, P. and Levy, D. (1987) Does the minimum drinking age affect traffic fatalities?, Journal of Policy Analysis and Management, 6, 180-192.

Becker, G. (1968) Crime and punishment: An economic approach, Journal of Political Economy, 76, 169-217.

Becker, G. and Murphy, K. (1988) A theory of rational addiction, Journal of Political Economy, 96, 675-700.

Becker, G., Grossman, M. and Murphy, K. (1994) An empirical analysis of cigarette addiction, The American Economic Review, 84, 396-418.

Benson, B., Mast, B., and Rasmussen, D. (1999) Deterring drunk driving fatalities: An economics of crime perspective, International Review of Law and Economics, 19, 205-225.

Benson, B., Mast, B., and Rasmussen, D. (2000) Can police deter drunk driving?, Applied Economics, 32, 357-366.

Chaloupka, F., Saffer, H. and Grossman, M. (1993) Alcohol-control policies and motorvehicle fatalities, Journal of Legal Studies, 22, 161-186.

Cook, P. (1988) Increasing the federal excise taxes on alcoholic beverages, Journal of Health Economics, 7, 89-91.

Cook, P. and Tauchen, G. (1984) The effect of minimum drinking age legislation on youthful auto fatalities, 1970-1977, Journal of Legal Studies, 13, 169-190.

Davidson, R. and Mackinnon, J.G. (1993) Estimation and inference in Econometrics, New York: Oxford University Press.

Dee, T. (1999) State alcohol policies, teen drinking and traffic fatalities, Journal of Public Economics, 72, 289-315.

Dee, T., Grabowski, D. and Morrisey, M. (2005) Graduated driver licensing and teen traffic fatalities, Journal of Health Economics, 24, 571-589.

Greene, W.H. (2003) Econometric analysis, $5^{\text {th }}$ edition. Upper Saddle River, NJ: PrenticeHall.

Grossman, M., Sindelar, J., Mullahy, J. and Anderson, R. (1993) Policy watch. alcohol and cigarette taxes, Journal of Economic Perspectives, 7, 211-222.

Hausman, J. (1978) Specification test in econometrics, Econometrica, 46, 1251-1271.

Kenkel, D. (1993a) Do drunk drivers pay their way? A note on optimal penalties for drunk driving, Journal of Health Economics, 12, 137-149.

Kenkel, D. (1993b) Drinking, driving, and deterrence: The effectiveness and social costs of alternative policies, Journal of Law and Economics, 36 (2), 877-913. 
Kenkel, D. (2005) Are alcohol tax hikes fully passed through to prices? Evidence from Alaska, The American Economic Review, 95 (2), 273-277.

Kenkel, D. and Koch, S. (2001) Deterrence and knowledge of the law: The case of drunk driving, Applied Economics, 33, 845-854.

Kenkel, D., Mathios, A. and Pacula, R. (2001) Economics of youth drug use, addiction and gateway effects, Addiction, 96, 151-164.

Maddala, G. (1983) Limited-dependent and qualitative variables in econometrics, Cambridge: Cambridge University Press.

Mast, B., Benson, B. and Rasmussen, D. (1999) Beer taxation and alcohol-related traffic fatalities, Southern Economic Journal, 66, 214-249.

McKenzie, R. B. (1991) Rational addiction, lagged demands and the efficiency of excise taxes: revisions of standard theory, Public Choice, 71, 33-41.

McKinnon, J.G., and White, H. (1985) Some heteroskedasticity-consistent covariance matrix estimators with improved finite sample properties, Journal of Econometrics, 29, 305-325.

Morrisey, M. and Grabowski, D. (2005) State motor vehicle laws and older drivers, Health Economics, 14, 407-419.

Pacula, R. (1998) Adolescent alcohol and marijuana consumption: is there really a gateway effect?, NBER Working Paper n. 6348.

Phelps, C. (1988) Death and taxes: an opportunity for substitution, Journal of Health Economics, 7, 1-24.

Reuter, P. (1988) Quantity illusions and paradoxes of drug interdiction: federal intervention into vice policy, Law and Contemporary Problems, 51, 233-252.

Ruhm, C. (1995) Economic conditions and alcohol problems, Journal of Health Economics, 14, 583-603.

Ruhm, C. (1996) Alcohol policies and highway vehicle fatalities, Journal of Health Economics, 15, 435-454.

Saffer, H. and Grossman, M. (1987) Beer taxes, the legal drinking age, and youth motor vehicle fatalities, NBER Working Papers 1914.

Scuffham, P. (2003) Economic factors and traffic crashes in New Zealand, Applied Economics, 35, 179-188.

Sen, A. (2001) Do stricter penalties deter drinking and driving? An empirical investigation of Canadian impaired driving laws, Canadian Journal of Economics, 34, 149-164.

Sloan, F., Reilly, B. and Schenzler, C. (1994) Tort liability versus other approaches for deterring careless driving, International Review of Law and Economics, 14, 53-71.

Smith, I. (1999) Road fatalities, modal split and Smeed's law, Applied Economics Letters, 6, 215-217. 
Spanish General Directorate of Traffic. (2004) Las principales cifras de sinestralidad vial. España 2004. Observatorio Nacional de Seguridad Vial: Madrid.

Spanish General Directorate of Traffic. (2005) Informe 2003-04. Observatorio Nacional de Seguridad Vial: Madrid.

Spanish National Anti-Drug Campaign. (2001) Más información, menos riesgos. Ministerio del Interior: Madrid.

White, H. (1980) Heteroscedasticity-consistent covariance matrix estimator and a direct test for heteroscedasticity, Econometrica, 48, 817-838.

Young, D. and Bielinska-Kwapisz, A. (2002) Alcohol taxes and beverage prices, National Tax Journal, 15, 57-73.

Young, D. and Bielinska-Kwapisz, A. (2003) Alcohol consumption, beverage prices, and measurement error, Journal of Studies on Alcohol, 64, 235-238.

Young, D. and Bielinska-Kwapisz, A. (2006) Alcohol prices, consumption, and traffic fatalities, Southern Economic Journal, 72(3), 690-703.

Young, D. and Likens, T. (2000) Alcohol regulation and auto fatalities, International Review of Law and Economics, 20, 107-126. 
Table 1. Deaths and traffic fatalities in Spain.

\begin{tabular}{|c|c|c|c|c|c|c|c|c|c|c|c|c|c|c|c|c|c|c|c|c|}
\hline & \multicolumn{8}{|c|}{ Number of deaths and percentage with respect to population } & \multicolumn{8}{|c|}{$\begin{array}{l}\text { Number of traffic fatalities and percentage with respect to } \\
\text { population }\end{array}$} & \multicolumn{4}{|c|}{$\begin{array}{l}\text { Percentage of traffic fatalities } \\
\text { with respect to total number } \\
\text { of deaths }\end{array}$} \\
\hline & \multicolumn{2}{|c|}{1996} & \multicolumn{2}{|c|}{1998} & \multicolumn{2}{|c|}{2000} & \multicolumn{2}{|c|}{2002} & \multicolumn{2}{|c|}{1996} & \multicolumn{2}{|c|}{1998} & \multicolumn{2}{|c|}{2000} & \multicolumn{2}{|c|}{2002} & 1996 & 1998 & 2000 & 2002 \\
\hline & N. & $\%$ & N. & $\%$ & N. & $\%$ & N. & $\%$ & N. & $\%$ & N. & $\%$ & N. & $\%$ & N. & $\%$ & $\%$ & $\%$ & $\%$ & $\%$ \\
\hline Andalusia & 59,562 & 0.82 & 61,619 & 0.84 & 32,520 & 0.44 & 62,697 & 0.83 & 920 & 0.01 & 1005 & 0.01 & 856 & 0.01 & 858 & 0.01 & 1.54 & 1.63 & 2.63 & 1.37 \\
\hline Aragon & 12,480 & 1.04 & 13,002 & 1.09 & 6,740 & 0.56 & 12,985 & 1.06 & 156 & 0.01 & 213 & 0.02 & 219 & 0.02 & 190 & 0.02 & 1.25 & 1.64 & 3.25 & 1.46 \\
\hline Asturias & 12,156 & 1.11 & 12,259 & 1.12 & 6,359 & 0.59 & 12,424 & 1.14 & 166 & 0.02 & 159 & 0.01 & 177 & 0.02 & 134 & 0.01 & 1.37 & 1.3 & 2.78 & 1.08 \\
\hline Balers & 6,789 & 0.88 & 7,079 & 0.88 & 3,839 & 4.34 & 7,114 & 0.77 & 117 & 0.02 & 114 & 0.01 & 137 & 0.01 & 108 & 0.01 & 1.72 & 1.61 & 3.57 & 1.52 \\
\hline Canaries & 11,046 & 0.68 & 11,724 & 0.71 & 6,663 & 0.39 & 11,863 & 0.64 & 183 & 0.01 & 212 & 0.01 & 212 & 0.01 & 136 & 0.01 & 1.66 & 1.81 & 3.18 & 1.15 \\
\hline Cantabria & 5,189 & 0.97 & 5,167 & 0.97 & 2,761 & 0.52 & 5,278 & 0.96 & 52 & 0.01 & 74 & 0.01 & 62 & 0.01 & 53 & 0.01 & 1 & 1.43 & 2.25 & 1 \\
\hline Castilla-Leon & 25,118 & 0.99 & 25,970 & 1.03 & 13,649 & 0.55 & 26,349 & 1.05 & 469 & 0.02 & 421 & 0.02 & 444 & 0.02 & 435 & 0.02 & 1.87 & 1.62 & 3.25 & 1.65 \\
\hline Castilla-Mancha & 16,832 & 0.97 & 17,141 & 0.99 & 8,624 & 0.49 & 17,577 & 0.98 & 234 & 0.01 & 244 & 0.01 & 272 & 0.02 & 248 & 0.01 & 1.39 & 1.42 & 3.15 & 1.41 \\
\hline Catalonia & 54,036 & 0.88 & 56,052 & 0.9 & 29,235 & 0.46 & 57,862 & 0.88 & 756 & 0.01 & 881 & 0.01 & 925 & 0.01 & 811 & 0.01 & 1.4 & 1.57 & 3.16 & 1.4 \\
\hline Valencia & 35,928 & 0.89 & 36,383 & 0.9 & 19,320 & 0.47 & 38,023 & 0.87 & 579 & 0.01 & 640 & 0.02 & 595 & 0.01 & 569 & 0.01 & 1.61 & 1.76 & 3.08 & 1.5 \\
\hline Extremadura & 10,508 & 0.97 & 10,623 & 0.98 & 5,405 & 0.5 & 10,549 & 0.97 & 144 & 0.01 & 148 & 0.01 & 156 & 0.01 & 132 & 0.01 & 1.37 & 1.39 & 2.89 & 1.25 \\
\hline Galicia & 28,879 & 1.04 & 28,103 & 1.02 & 14,716 & 0.54 & 28,353 & 1.03 & 610 & 0.02 & 641 & 0.02 & 563 & 0.02 & 495 & 0.02 & 2.11 & 2.28 & 3.83 & 1.75 \\
\hline Madrid & 36,804 & 0.73 & 37,711 & 0.74 & 19,615 & 0.38 & 39,281 & 0.71 & 446 & 0.01 & 461 & 0.01 & 452 & 0.01 & 417 & 0.01 & 1.21 & 1.22 & 2.3 & 1.06 \\
\hline Murcia & 8,581 & 0.78 & 9,060 & 0.81 & 4,860 & 0.42 & 9,441 & 0.76 & 153 & 0.01 & 201 & 0.02 & 212 & 0.02 & 194 & 0.02 & 1.78 & 2.22 & 4.36 & 2.05 \\
\hline Navarre & 4,690 & 0.89 & 4,816 & 0.9 & 2,589 & 0.47 & 4,989 & 0.87 & 84 & 0.02 & 100 & 0.02 & 102 & 0.02 & 76 & 0.01 & 1.79 & 2.08 & 3.94 & 1.52 \\
\hline Basque Country & 18,035 & 0.85 & 18,153 & 0.86 & 9,802 & 0.46 & 18,627 & 0.88 & 271 & 0.01 & 314 & 0.01 & 304 & 0.01 & 269 & 0.01 & 1.5 & 1.73 & 3.1 & 1.44 \\
\hline Rioja & 2,549 & 0.95 & 2,588 & 0.97 & 1,388 & 0.52 & 2,634 & 0.93 & 39 & 0.01 & 61 & 0.02 & 49 & 0.02 & 59 & 0.02 & 1.53 & 2.36 & 3.53 & 2.24 \\
\hline Total & 349,182 & 0.88 & 357,450 & 0.89 & 160,257 & 0.4 & 366,046 & 0.87 & 5,379 & 0.01 & 5,889 & 0.01 & 5,688 & 0.01 & 5,183 & 0.01 & 1.54 & 1.65 & 3.55 & 1.42 \\
\hline
\end{tabular}


Table 2. Endogeneity test for the variable alcohol consumption in the equation (7)

\begin{tabular}{lcc}
\hline \multirow{2}{*}{ Index of Mortality } & Hausman Test & DWH Test \\
\cline { 2 - 3 } & $\begin{array}{c}\chi^{2}(1 \text { degree of freedom) } \\
\text { (significance level) }\end{array}$ & $\begin{array}{c}\text { F-snedecor value }(1,48) \\
\text { (significance level) }\end{array}$ \\
\hline Whole Survey: & 1.28 & 1,29 \\
Rational addiction & $(0.257)$ & $(0,261)$ \\
\hline Whole Survey: & 0.76 & 0,76 \\
Myopic addiction & $(0.383)$ & $(0,388)$ \\
\hline
\end{tabular}


Table 3. Variables and descriptive statistics (1998-2002).

\begin{tabular}{|c|c|c|}
\hline Variables & Description & $\begin{array}{c}\text { Mean } \\
\text { (S. Deviation) }\end{array}$ \\
\hline \multicolumn{3}{|c|}{ Survey of Deaths by Cause, Spanish National Institute of Statistics } \\
\hline$Y_{i t}=R F T$ & Rate of traffic fatalities (logistic transformation) by Autonomous Communities. & $\begin{array}{l}0.016 \\
(0.03)\end{array}$ \\
\hline \multicolumn{3}{|c|}{ Statistic Yearbook about Labor Issues, Spanish Labor Ministry } \\
\hline INCOMEDF & Labor cost per worker by Autonomous Communities. (in Euros deflated to 2001) & $\begin{array}{l}1313.932 \\
(157.777)\end{array}$ \\
\hline \multicolumn{3}{|c|}{ Consumption Household Survey, Spanish Ministry of Food, Agriculture and Fishing } \\
\hline$C A$ & $\begin{array}{l}\text { Annual alcohol consumption per capita (Kg.) by Autonomous Communities. The } \\
\text { quantities have been corrected by ethanol content (by } 1 \text { beer; } 2 \\
\text { wine/champagne/cider; } 8 \text { strong liquors). }\end{array}$ & $\begin{array}{l}53.560 \\
(14.910)\end{array}$ \\
\hline BEERPRICE & Average price of beer in Euros per kg. by Autonomous Communities. & $\begin{array}{c}1.155 \\
(0.097)\end{array}$ \\
\hline \multicolumn{3}{|c|}{ Statistic Yearbook, General Directorate of Traffic } \\
\hline $\operatorname{SANCTION}(t-1)$ & $\begin{array}{l}\text { Number of traffic sanctions by Autonomous Communities for the period } t-1 \\
\text { (numbers in thousand). }\end{array}$ & $\begin{array}{l}133.650 \\
(179.099)\end{array}$ \\
\hline$N D A$ & $\begin{array}{l}\text { Number of novice drivers type A and A1 (every } 1000 \text { citizens) by Autonomous } \\
\text { Communities for the period t. }\end{array}$ & $\begin{array}{l}0.927 \\
(1.656)\end{array}$ \\
\hline \multicolumn{3}{|c|}{ CPI, Spanish National Institute of Statistics } \\
\hline CPIA & Present harmonized CPI of alcoholic beverages by Autonomous Communities. & $\begin{array}{l}108.580 \\
(19.539)\end{array}$ \\
\hline$C P I A(t-1)$ & Lagged harmonized CPI of alcoholic beverages by Autonomous Communities. & $\begin{array}{l}105.205 \\
(19.903)\end{array}$ \\
\hline$C P I A(t+1)$ & Future harmonized CPI of alcoholic beverages by Autonomous Communities. & $\begin{array}{l}109.001 \\
(15.366)\end{array}$ \\
\hline \multicolumn{3}{|c|}{ SPATIAL DUMMY VARIABLES } \\
\hline NORTH & $\begin{array}{l}\text { Dummy variable that takes the value } 1 \text { if the observation is related to an } \\
\text { Autonomous Community placed in the North (Asturias, Cantabria, Galicia, } \\
\text { Navarre and Basque Country), } 0 \text { otherwise. }\end{array}$ & $\begin{array}{l}0.278 \\
(0.450)\end{array}$ \\
\hline SOUTH & $\begin{array}{l}\text { Dummy variable that takes the value } 1 \text { if the observation is related to an } \\
\text { Autonomous Community placed in the South (Andalucia, Murcia, Ceuta and } \\
\text { Melilla), } 0 \text { otherwise. }\end{array}$ & $\begin{array}{l}0.167 \\
(0.375)\end{array}$ \\
\hline EAST & $\begin{array}{l}\text { Dummy variable that takes the value } 1 \text { if the observation is related to an } \\
\text { Autonomous Community placed in the East (Aragon, Catalonia and Valencia), } 0 \\
\text { otherwise. }\end{array}$ & $\begin{array}{l}0.167 \\
(0.375)\end{array}$ \\
\hline CENTER & $\begin{array}{l}\text { Dummy variable that takes the value } 1 \text { if the observation is related to an } \\
\text { Autonomous Community placed in the Center (C. Mancha, C. Leon, Extremadura } \\
\text { and Rioja), } 0 \text { otherwise. }\end{array}$ & $\begin{array}{l}0.222 \\
(0.418)\end{array}$ \\
\hline ISLANDS & $\begin{array}{l}\text { Dummy variable that takes the value } 1 \text { if the observation is related to an } \\
\text { Autonomous Community placed in the Islands (Balers and Canaries), } 0 \text { otherwise. }\end{array}$ & $\begin{array}{l}0.111 \\
(0.316)\end{array}$ \\
\hline$M A D R I D$ & $\begin{array}{l}\text { Dummy variable that takes the value } 1 \text { if the observation is related to an } \\
\text { Autonomous Community placed in the Madrid, } 0 \text { otherwise. }\end{array}$ & $\begin{array}{l}0.056 \\
(0.230)\end{array}$ \\
\hline
\end{tabular}


Table 4. Estimation of alcohol consumption.

\begin{tabular}{|c|c|c|c|c|c|c|c|c|}
\hline & \multicolumn{4}{|c|}{ RATIONAL ADDICTION } & \multicolumn{4}{|c|}{ MYOPIC ADDICTION } \\
\hline & Coefficient & S. Deviation & Sign. & Elasticity & Coefficient & S. Deviation & Sign. & Elasticity \\
\hline CPIA & 0.0153 & 0.0124 & & 0.3097 & 0.0214 & 0.0096 & $* *$ & 0.4311 \\
\hline$C P I A(t-1)$ & -0.0312 & 0.0092 & $* * *$ & -0.6096 & -0.0315 & 0.0092 & $* * *$ & -0.6150 \\
\hline$C P I A(t+1)$ & 0.0082 & 0.0105 & & 0.1667 & - & - & - & \\
\hline INCOMEDF & 0.0021 & 0.0008 & $* * *$ & 0.5255 & 0.0022 & 0.0008 & $* * *$ & 0.5317 \\
\hline NORTH & 1.3181 & 0.4598 & $* * *$ & 0.0724 & 1.3323 & 0.4582 & $* * *$ & 0.0732 \\
\hline SOUTH & 1.4784 & 0.5781 & $* * *$ & 0.0325 & 1.4871 & 0.5765 & $* * *$ & 0.0327 \\
\hline$E A S T$ & 1.3146 & 0.4929 & $* * *$ & 0.0433 & 1.3205 & 0.4915 & $* * *$ & 0.0435 \\
\hline CENTER & 0.8601 & 0.5471 & & 0.0378 & 0.8765 & 0.5452 & & 0.0385 \\
\hline ISLANDS & 0.9267 & 0.5663 & $*$ & 0.0204 & 0.9359 & 0.5647 & $*$ & 0.0206 \\
\hline$M A D R I D^{\mathrm{a})}$ & - & - & - & & - & - & - & \\
\hline YEAR 2002 & 0.5053 & 0.4141 & & 0.0189 & 0.6355 & 0.378 & $*$ & 0.0237 \\
\hline YEAR 2001 & - & - & - & & - & - & - & \\
\hline YEAR 2000 & -0.0152 & 0.3594 & & -0.0006 & 0.1724 & 0.2666 & & 0.0064 \\
\hline YEAR 1999 & 2.8487 & 0.3445 & $* * *$ & 0.1064 & 3.0124 & 0.2726 & $* * *$ & 0.1125 \\
\hline YEAR 1998 & 0.1384 & 0.3626 & & 0.0052 & 0.3048 & 0.2925 & & 0.0114 \\
\hline INTERCEPT & 1.455 & 1.4523 & & & 1.552 & 1.443 & & \\
\hline $\begin{array}{l}\text { F-Snedecor } \\
\text { (Prob) }\end{array}$ & \multicolumn{4}{|c|}{$18.78(0.00)$} & \multicolumn{4}{|c|}{$20.41(0.00)$} \\
\hline$R^{2}$ (corrected) & \multicolumn{4}{|c|}{0.7335} & \multicolumn{4}{|c|}{0.7349} \\
\hline$R^{2}$ & \multicolumn{4}{|c|}{0.7747} & \multicolumn{4}{|c|}{0.7728} \\
\hline $\begin{array}{l}\text { Akaike info } \\
\text { criterion }\end{array}$ & \multicolumn{4}{|c|}{2.4639} & \multicolumn{4}{|c|}{2.4490} \\
\hline \multicolumn{9}{|c|}{$\begin{array}{l}\text { Note: } * * \text { indicates individual significance at the } 1 \% \text { level; } * * 5 \% \text { level; } * 10 \% \text { level. } \\
\text { - Reference variable in a) } \\
\text { - The dependent variable Alcohol Consumption has been divided by } 10 . \\
\text { - The elasticity terms have been calculated from the marginal effect using the routine in STATA9.0 named "mfx". The } \\
\text { elasticity terms have been evaluated at the mean of the independent variables. }\end{array}$} \\
\hline
\end{tabular}

Editorial Office, Dept of Econōmics, Warwick University, Coventry CV4 7AL, UK 
Table 5. Estimation of the rate of traffic fatalities.

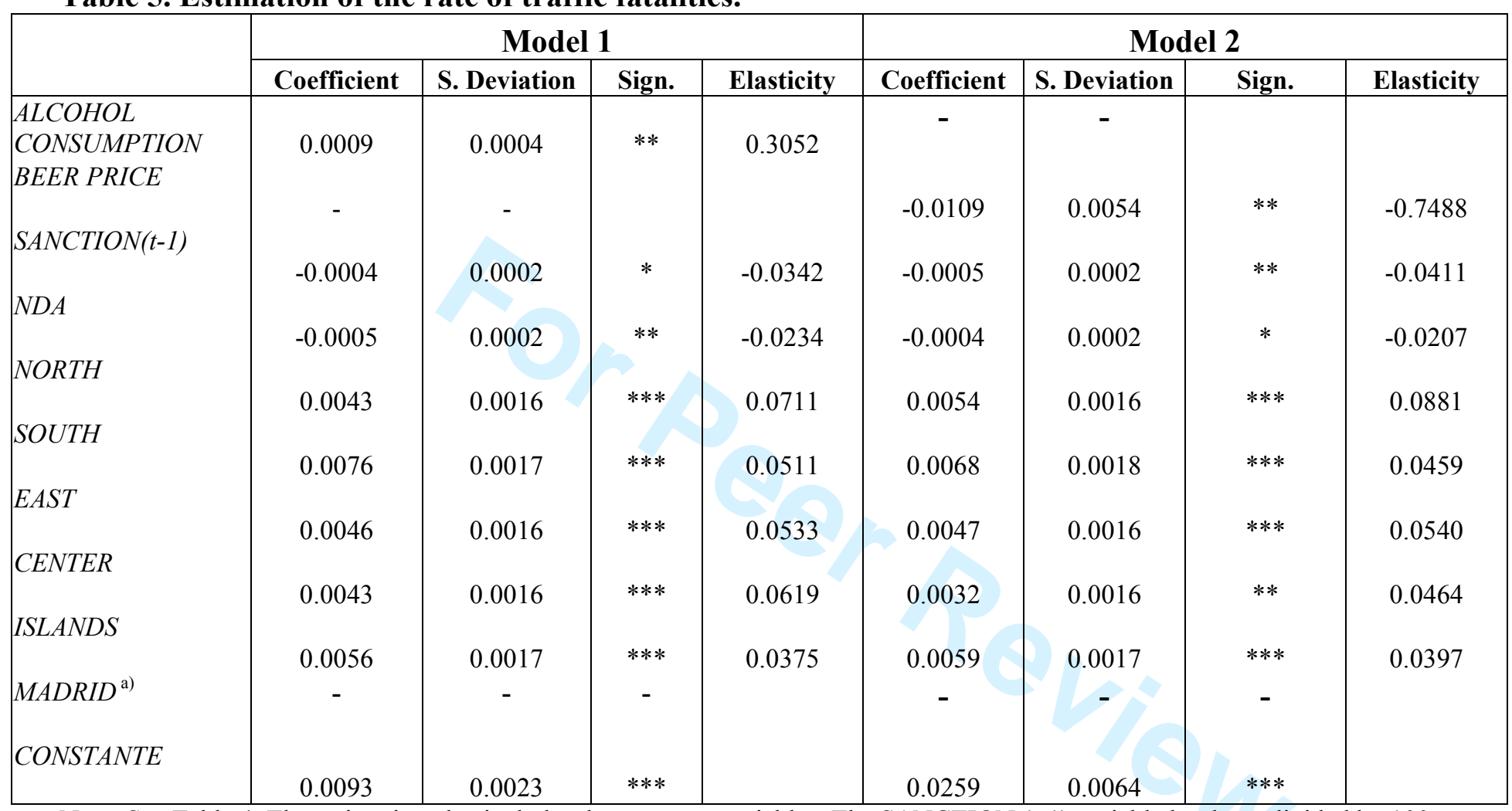

Note: See Table 4. The estimation also includes dummy year variables. The SANCTION (t-1) variable has been divided by 100. 
Table 6. Prices and taxes of beer.

\begin{tabular}{|c|c|c|c|c|c|c|}
\hline \multirow[b]{2}{*}{ Region } & \multirow{2}{*}{$\begin{array}{c}\text { Price } \\
\text { before } \\
\text { taxes } \\
\text { (Euros) }\end{array}$} & \multirow[b]{2}{*}{$\begin{array}{l}\text { Taxes } \\
(\%)\end{array}$} & \multirow{2}{*}{$\begin{array}{c}\text { Price } \\
\text { after } \\
\text { taxes } \\
\text { (Euros) }\end{array}$} & \multicolumn{3}{|c|}{ Tax increase (10\%) } \\
\hline & & & & $\begin{array}{l}\text { Taxes } \\
(\%)\end{array}$ & $\begin{array}{l}\text { Price after taxes } \\
\text { (Euros) }\end{array}$ & $\begin{array}{c}\text { Price increase } \\
(\%)\end{array}$ \\
\hline Andalucia & 0.12 & 16.81 & 2.27 & 18.49 & 2.48 & 9.44 \\
\hline Aragon & 0.14 & 16.70 & 2.61 & 18.37 & 2.86 & 9.43 \\
\hline Asturias & 0.14 & 16.69 & 2.63 & 18.35 & 2.88 & 9.43 \\
\hline The Balearic Islands & 0.14 & 16.72 & 2.53 & 18.39 & 2.77 & 9.43 \\
\hline The Canary Islands & 0.15 & 16.68 & 2.67 & 18.34 & 2.92 & 9.43 \\
\hline Cantabria & 0.15 & 16.68 & 2.65 & 18.34 & 2.90 & 9.43 \\
\hline C. Mancha & 0.12 & 16.80 & 2.28 & 18.48 & 2.50 & 9.44 \\
\hline C. Leon & 0.13 & 16.78 & 2.35 & 18.45 & 2.57 & 9.44 \\
\hline Catalonia & 0.14 & 16.72 & 2.54 & 18.39 & 2.78 & 9.43 \\
\hline Valencia & 0.12 & 16.81 & 2.25 & 18.49 & 2.46 & 9.44 \\
\hline Extremadura & 0.14 & 16.72 & 2.53 & 18.39 & 2.77 & 9.43 \\
\hline Galicia & 0.14 & 16.71 & 2.56 & 18.38 & 2.80 & 9.43 \\
\hline Madrid & 0.14 & 16.72 & 2.51 & 18.39 & 2.74 & 9.43 \\
\hline Murcia & 0.13 & 16.78 & 2.33 & 18.45 & 2.55 & 9.44 \\
\hline Navarra & 0.14 & 16.71 & 2.57 & 18.38 & 2.82 & 9.43 \\
\hline The Basque Country & 0.15 & 16.67 & 2.72 & 18.33 & 2.98 & 9.43 \\
\hline Rioja & 0.12 & 16.81 & 2.25 & 18.49 & 2.46 & 9.44 \\
\hline
\end{tabular}

Source: Consumption Household Survey, Spanish Ministry of Food, Agriculture and Fishing (2000). Average price of a beer $(33 \mathrm{cc}$.) acquired in a supermarket.

Law 37/1992 of December 29 and Law 38/1992 of December 28. 